\title{
Research on immersive teaching mode of e-commerce course group oriented by vocational abilities training
}

\author{
Jinbo Bai ${ }^{1, a}$, Hongbo $\mathrm{Li}^{2, b,{ }^{*}}$ \\ ${ }^{1}$ Economics \& Management College, Zhaoqing University, Zhaoqing, China \\ ${ }^{2}$ School of Computer Science and Software, Zhaoqing University, Zhaoqing, China \\ ahljbjb@126.com, bislhb@126.com \\ ${ }^{*}$ Corresponding author
}

Keywords: Electronic commerce, Vocational abilities, Project-driven, Immersive, Teaching mode.

\begin{abstract}
With the rapid development of e-commerce, the shortage of talents related to e-commerce has become increasingly prominent. The knowledge and abilities of students cultivated under the traditional teaching mode are seriously out of line with each other. Most of them lack the cognition of vocational ability requirements and have poor practical ability. Although they are graduates of e-commerce major, they are not competent for the practical work of e-commerce related posts. In order to solve above problems, this paper puts forward an immersive teaching mode of e-commerce course group, which is oriented to the cultivation of vocational abilities. The promotion and application of the research results can realize the seamless connection between talent training and enterprise demands and effectively improve the quality of talent training, so as to on the one hand effectively improve the employment rate of students, on the other hand effectively serve the regional economic development, eventually achieve a win-win situation among students, schools, enterprises and society.
\end{abstract}

\section{Introduction}

With the rapid development of the Internet, e-commerce is booming. However, with the rapid development of e-commerce, the shortage of talents related to e-commerce has become increasingly prominent, which has become an important factor hindering the development of e-commerce. In order to serve the regional economic development, colleges and universities have increased the strength of e-commerce personnel training. However, students' knowledge and abilities are seriously disjointed under the traditional teaching mode. Most of them lack the cognition of vocational ability requirements and have poor practical abilities. Although they are graduates of e-commerce major, they are not competent for practical work related to e-commerce.

E-commerce is a fast growing industry. In the face of the rapidly changing and competitive market environment, enterprises often have no time to train new employees and wait for them to grow up and adapt to work. What enterprises need is the man who can able to put in immediately and competent for work. Thus, the phenomenon of labor shortage and employment difficulty co-exists. On the one hand, enterprises need a lot of talents related to e-commerce; on the other hand, a large number of e-commerce graduates cannot find suitable jobs. In the face of this situation, colleges and universities, especially those that are transforming into application-oriented ones, urgently need to reintegrate teaching resources, reform and innovate mode of teaching, so as to effectively help students keep pace with the times in aspects of knowledge, skills and quality, and effectively improve the students' practical application abilities, so that the school personnel training can truly serve local and regional economic development needs.

To this end, this paper will take vocational ability cultivation as the orientation, aiming at the teaching reform and construction of series courses of e-commerce specialty, and launch the project-driven immersive teaching mode research. This article will elaborate a teaching reform schema which through cooperation between colleges and enterprises introduce enterprises' actual projects into campus, and taking these actual projects as drive, students as the main body, and 
abilities as the standard, build a project learning environment which students can immerse in. This project learning environment taking the knowledge and abilities required by students' future practical work as the guidance, guide students through collaborative learning and practice of team to complete the independent construction of knowledge needed for future jobs, pre-job training of professional skills and comprehensive improvement of professional quality required.

\section{Related works}

Immersive teaching[1-4] originated in Canada in the 1960s, is a beneficial attempt of Canadian French teaching and has been proved that it is a kind of very effective teaching mode for non native language. Therefore, this teaching mode has been paid more and more attention, and has been widely applied in Canada and the United States with great success.

In recent years, Chinese scholars have begun to pay attention to, study and introduce immersive teaching. At CNKI website, 125 papers were retrieved under the retrieval condition of "title: immersive teaching". The earliest paper on immersive teaching was immersive French teaching in Canada published by professor wang zhu of Beijing foreign studies university in 1995, which introduced the basic framework, characteristics and advantages of immersive teaching in Canadian French. After that, a few sporadic studies can be seen, and more studies are mainly concentrated in the last few years. A total of 64 research papers have been published, accounting for $51 \%$ of the total detection. Most of them applied immersive teaching to language teaching, especially in non-native language teaching, and few studies applied it to other courses.

In recent years, the research on the training mode of e-commerce talents has been the focus of attention of various universities and enterprises. The relevant research results provide some experience for reference, but there is no immersive teaching research oriented by vocational ability training.

\section{Teaching mode}

\subsection{Design of teaching mode}

The teaching mode established in this study consists of the following steps.

The first step is to understand the actual demands for talents of e-commerce enterprises and the requirements for professional abilities of e-commerce related posts through investigation, and forms a document, as shown in Fig. 1. In this step, teachers and the hired enterprise mentors jointly identify the required professional abilities and further refine the core professional abilities.

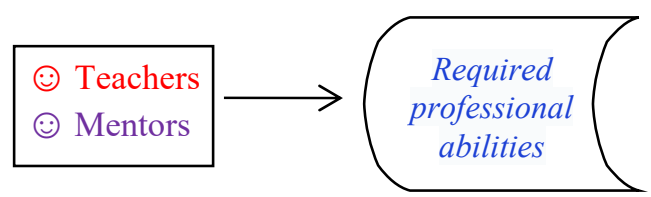

Fig. 1. Teachers and enterprise mentors jointly determining professional abilities requirements

In the second step, teachers analyze and sort out the vocational skill requirements of e-commerce related positions and form a document on the basis of preliminary investigation, as shown in Fig. 2.

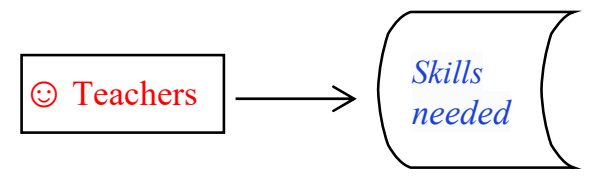

Fig. 2. Teachers determining the skill requirements

The third step is to integrate teaching resources and build learning content documents according to the identified skill needs, as shown in Fig. 3.

The fourth step is to determine and provide enterprise projects based on full discussion between teachers and enterprise mentors, as shown in Fig. 4. Because some conditions are not present, the 
project can be simplified, allowing it to be a "fake" or "quasi" project which approximates the actual project.

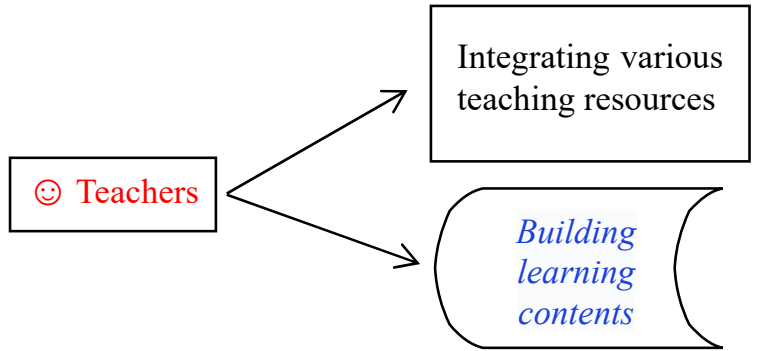

Fig. 3. Teachers integrating teaching resources and constructing learning content documents

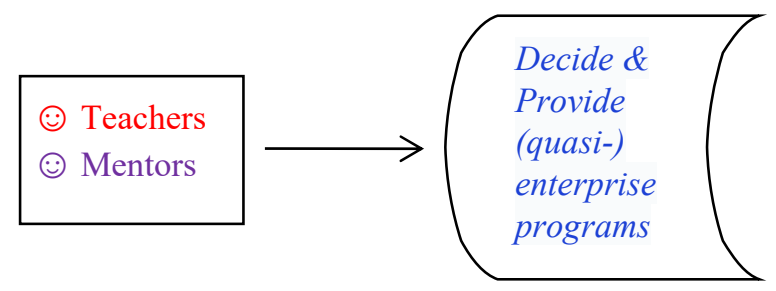

Fig. 4. Teachers and business mentors identifying and providing enterprise projects

In the fifth step, teachers and students teach and learn skills and knowledge respectively, as shown in Fig. 5.

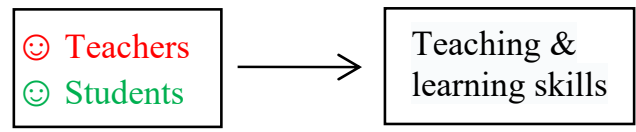

Fig. 5. Teachers and students teaching and learning skills and knowledge respectively

In the sixth step, students complete enterprise projects by immersive learning, as shown in Fig. 6.

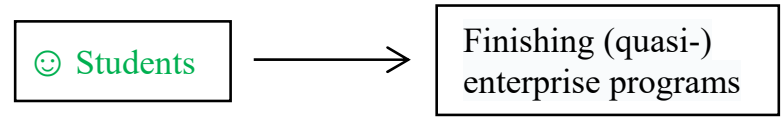

Fig. 6. Teachers and students teaching and learning skills and knowledge respectively

In steps 5 and 6, students as the main body of learning knowledge and skills, may offer some feedback, add some professional abilities and skills ignored by teachers and mentors, and thus also become builders and participants of professional abilities and skill requirements document construction, as shown in Fig. 7. After students participate in the construction of vocational ability and skill requirement document, all of the steps constitute a dynamic closed loop and enters a benign development stage.

\subsection{Advantages of the teaching mode}

First, the immersive teaching mode oriented by vocational ability cultivation can effectively activate students' subjective consciousness, effectively improve the effectiveness of students' participation, and make students become the independent constructors of knowledge.

Second, the immersive teaching mode oriented by vocational ability cultivation can effectively help students under the practical working situation of competition, cooperation and consultation exercise and improve their awareness and ability of teamwork, improve their communication and coordination ability, and realize the comprehensive improvement of knowledge, ability and professional quality.

Third, immersive teaching based on school-enterprise cooperation and oriented to professional ability training will eventually realize the integration of talent training and service for regional economic development, and achieve a win-win situation among schools, students, enterprises and society. 


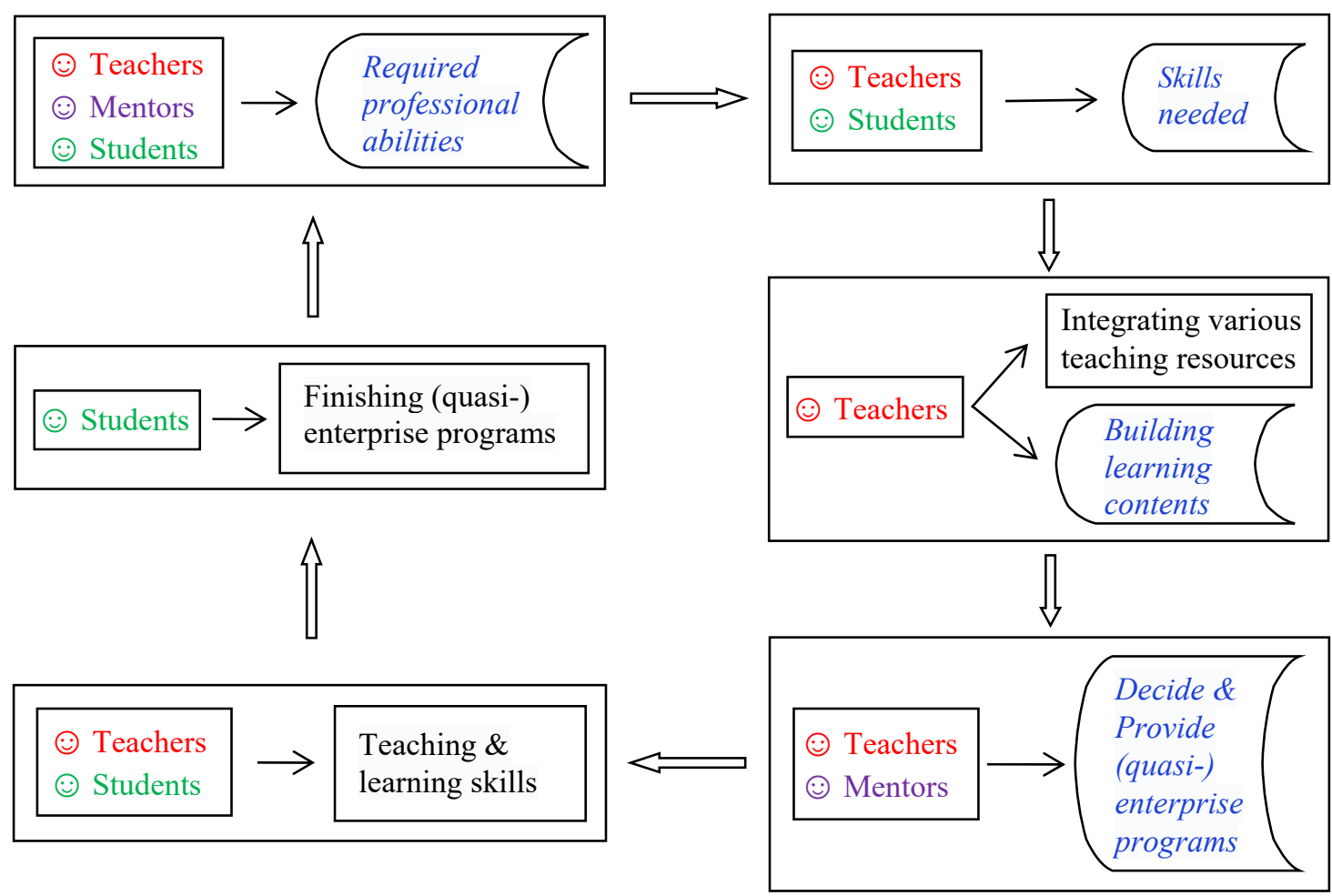

Fig. 7. Teaching mode in dynamic evolution

\section{Conclusions}

Aiming at the problem that students' knowledge and abilities are seriously out of line under the traditional teaching mode, this paper puts forward an immersive teaching mode of e-commerce course group, which is oriented by vocational ability training. The promotion and application of the research results can effectively improve the quality of talent training, and realize the seamless connection between talent training and enterprise needs, so as to on the one hand effectively improve the employment rate of students, and on the other hand effectively serve the regional economic development.

\section{Acknowledgment}

This research was financially supported by the Research Project of Education Development Research Institute of Zhaoqing City (Grant No. ZQJYY2017002).

\section{References}

[1] L. Cinganotto, English language, immersive teaching and game-based learning in a teacher training project promoted by Indire,Form@re-Open Journal per la formazione in rete, vol. 17, pp. 158-175, 2017.

[2] M. Mentzelopoulos, J. Parrish, P. Kathrani, and D. Economou, REVRLaw: an immersive way for teaching criminal law using virtual reality, In International Conference on Immersive Learning, pp. 73-84, 2016.

[3] L.M. Ditzel, K. Hogarth, and R. Lesa, Immersive learning in nursing education: results of a study, Journal of Nursing Education and Practice, vol. 7, pp. 120, 2017.

[4] Jinbo Bai, Hongbo Li, Jianping Chen, Research on constructivism-based collaborative learning mode, Proceedings of the 2nd International Conference on Economics and Management, Education, Humanities and Social Sciences (EMEHSS 2018), pp.431-434, 2018. 